\title{
CUSTOMER SEGMENTATION IN CUSTOMER RELATIONSHIP MANAGEMENT BASED ON DATA MINING
}

\author{
Yun Chen, Guozheng Zhang, Dengfeng Hu, Shanshan Wang
}

School of Public Economy Administration of Shanghai University of finance \& economics, Shanghai, 200433, China. E_mail:guozhengzhang@gmail.com

\begin{abstract}
Customer relationship management (CRM) is the new management principle that adapts the business enterprise strategy shift from product-centric to customer-centric. Customer segmentation is one of the core functions of customer relationship management (CRM). This paper will build customer segmentation function model based on data mining, and summarizes the advantages of customer segmentation function model based on data mining in customer relationship management(CRM).
\end{abstract}

Key words: Customer Relationship Management; Customer Segmentation; Data Mining; Customer Value;

\section{INTRODUCTION}

Over the past decade, there has been an explosion of interest in customer relationship management (CRM) by both academics and executives [1]. Organizations are realizing that customers have different economic value to the company, and they are subsequently adapting their customer offerings and communications strategy accordingly. Thus, organizations are, in essence, moving away from product- or brand-centric marketing toward a customer-centric approach.

Currently research demonstrates that the implementation of CRM activities generates better firm performance when managers focus on maximizing the value of the customer [2]. Customer segmentation is the

The project is supported by the Shanghai Shuguang Project of China under the grant No: $05 \mathrm{SG} 38$

Please use the following format when citing this chapter:

Chen, Yun, Zhang, Guozheng, Hu, Dengfeng, Wang, Shanshan, 2006, in International Federation for Information Processing (IFIP), Volume 207, Knowledge Enterprise: Intelligent Strategies In Product Design, Manufacturing, and Management, eds. K. Wang, Kovacs G., Wozny M., Fang M., (Boston: Springer), pp. 288-293. 
base of how to maximize the value of customer. Again and again firms find that the Pareto principle holds true, with $20 \%$ of the customer base generating $80 \%$ of the profits. Both researchers and managers need to evaluate and select segmentations in order to design and establish different strategies to maximize the value of customer.

\section{LIMITATION OF TRADITIONAL CUSTOMER SEGMENTATION METHODS AND ADVANTAGE OF DATA MINING METHOD}

\subsection{Traditional segmentation methods and limitation}

Segmentation can be seen as a simplification of the messy complexity of dealing with numerous individual customers, each with distinct needs and potential value [4].Traditional customer segmentations methods commonly based on experiential classification methods or simple statistical methods. Traditional statistical methods segment customer according to simple behavior character or attribute character such as the product category purchased or the region resided in.

These segmentation methods couldn't do more complex analysis that what kind of customers has high potential value and what kind has high credit. With the extensive application of EC and CRM, enterprises have accumulated more and more customer data. Traditional technique such as multiple regressions cannot cope with this level of complexity. Consequently, the reliability and validity of the statistical functions used to generate segmentations or to build predictive models becomes a possible contributory factor to CRM user dissatisfaction [7].

\subsection{Data mining and it's Advantage}

Data mining can be considered a recently developed methodology and technology, coming into prominence in 1994. The SAS Institute defines data mining as the process of selecting, exploring and modeling large amounts of data to uncover previously unknown patterns of data [5]. Accordingly, data mining can be considered a process and a technology to detect the previously unknown in order to gain competitive advantage.

Data mining uses neural networks, decision trees, link analysis, and association analysis to discover useful trends and patterns from the extracted data [6]. Data mining can yield important insights including prediction 
models and associations that can help companies understand their customers better. Many large companies today have terabytes of data, within which they could probably find more information about their customers, markets, and competition than they would ever need. Data mining enables marketers to better extract valuable business information from the 'mountains of data' in a firm's systems. It is a potential solution to a big problem facing many companies: an overabundance of data and a relative dearth of staff, technology, and time to transform numbers and notes into meaningful information about existing and prospective customers. Data mining enables a firm to measure consumer behavior on the basis of 100 or more attributes, instead of the three or four associated with traditional statistical modeling [7]. The more attributes a firm uses, the greater the complexity of the data and the greater the need for data mining tools.

\section{CUSTOMER SEGMENTATION MODEL BASED ON DATA MINING}

\subsection{Customer Segmentation model}

As practitioners are enthusiastically seeking out groups of profitable customers whose loyalty is steady, some academics are beginning to question whether segments are actually stable entities and more fundamentally whether they really exist at all[7]. Segmentation method based on data mining put up by this paper can solve above problems because the model could study from new information that input afterward and get new rules. It provides completely support to the dynamic management process of customer acquiring, customer keeping and customer value increasing, customer satisfaction and customer loyalty promoting.

Building the mapping relationship between the conception attribute and the customer is the key step of segmentation method based on data mining. Customer data contain dispersive and continues attribute. Setting each customer attribute as a dimension and setting each customer as a particle, the whole customers in enterprise can form a multidimensional space, which has been defined as the attribute space of the customer.

The mapping relationship between customers attributes and conception category can be constructed by analytic method, or by sample learning method. Analytic method analyzes the attribute character of each conception category should have, subsequently constructs the mapping relationship between attributes space and conception space. But much mapping relationship between attributes space and conception space weren't clear, it 
need use sample learning method constructing the mapping relationship [11]. Sample learning method automatically generalize the mapping relationship between attributes space and conception space by applying data mining technology on known conception category in enterprise database. The data mining process is called sample learning.

Assume $\mathrm{B}-\left\{\mathrm{G}_{1}, \mathrm{G}_{2}, \ldots, \mathrm{G}_{\mathrm{n}}\right\}$, we can confirm a group conception category by $\mathrm{B}, \mathrm{L}-\left\{\mathrm{L}_{1}, \mathrm{~L}_{2}, \ldots, \mathrm{L}_{\mathrm{p}}\right\}, C^{\prime} \subseteq C, \mathrm{C}^{\prime}$ is known customer category.

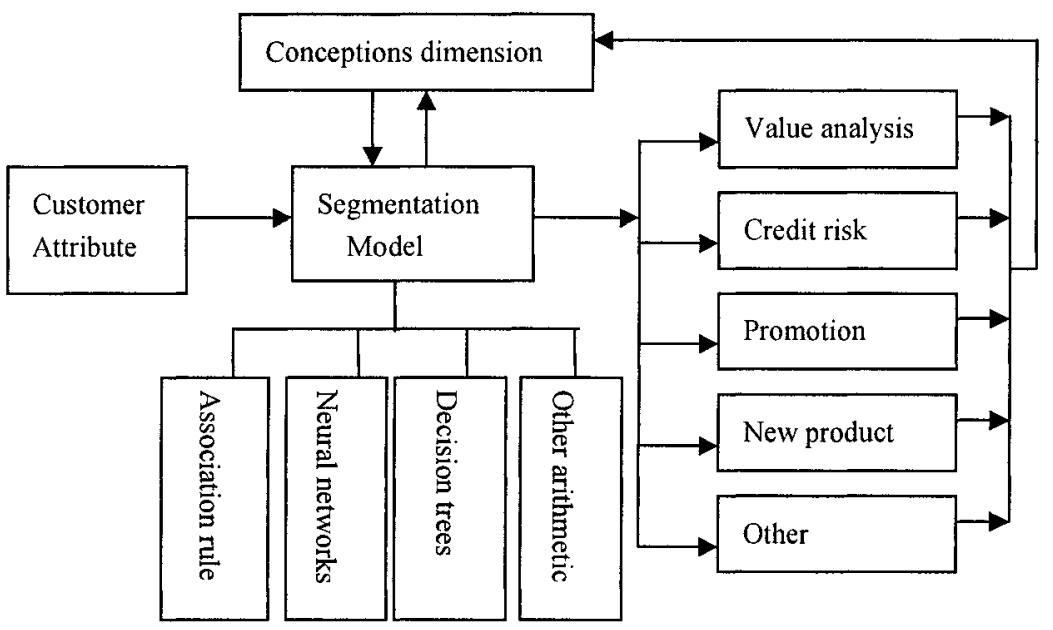

Figure ICustomer Segment Model based on data mining

The three steps of customer segmentation based on data mining:

(1) Ensuring mapping route. $\mathrm{p}$ : $\mathrm{C} \rightarrow \mathrm{L}$, set $\forall c \in C^{\prime}$, if $\mathrm{c} \in \mathrm{L}_{\mathrm{i}}$, then $\mathrm{p}(\mathrm{c})=\mathrm{L}_{\mathrm{i}}$.

(2) $\forall c \in C$, confirming which conception category c belong to by seeking the value of $\mathrm{p}(\mathrm{c})$.

(3) Rule creation and Function analysis. As showed in figure.1. The segmentation model applied data mining technology such as Association rule, Neural network, Decision tree, etc, as its method foundation. This segmentation model firstly segment customer according to the mapping relationship, subsequently processing various kind of business application.

1) Segmentation rule creation

Sort the customers with the Customer Segment Model and the Segment Function. After training the segment model, we get the segment rule or the 
network segment rule. We can effectively segment new customers based on the trained model.

2) Function Analysis

Function analysis includes customer value analysis, credit analysis and promotion analysis, etc, based on the foundation of the mapping relationship between customer and concept. Further on, new function requirement will be bring forward to CRM with the developing of the management practice. The new demand functions would be added to the conceptual dimension and reconstruct the mapping relationship with the customer characteristic.

\subsection{Advantage of the customer segmentation model based on data mining}

(1) Improving promotion effect

The customer segmentation based on the data mining can be helpful for the enterprises to make suitable promotion strategy, in suitable time, with suitable products and services, aiming at suitable customers.

(2) Analyzing customer value and customer loyalty

The customer value and the customer loyalty are important to enterpriser's stratagem and management tactics. Enterprises can confirm the rank of customer according to their expected value and loyalty analyzed by segmentation model based on data mining.

(3) Analyzing credit risk

Risk scoring is an effective way of evaluating certain specific types of customer risk, normally the risk of default.

(4) Instructing new products R\&D

Enterprises can find out the preference of theirs customers by customer analyzing based on data mining, and make sure that various demand will be realized in the new design.

(5) Confirming target market

Customer segmentation base on data mining can make targeted customer group clear and locate the market explicitly.

\section{CONCLUSIONS}

A key role of marketing is to identify the customers or segments with the greatest value-creating potential and target them successfully with corresponding marketing strategies to reduce the risk of these high lifetime value customers defecting to competitors [10]. In this construction mode, segmenting customer is the basic work of data mining according to known historic segmentation information. The training data used to construct 
segment forecast mode can be historic data or exogenous data that gain from experience or survey.

Because customer behavior is uncertain and inconsistent, researchers and managers should construct dynamic customer segmentation model in order to objectively reflect the characteristic. In customer-centric era, customer segmentation result is concern with the establishment of enterprise's stratagem and tactics. Best practice demands that marketers develop their understanding of customer segmentation based on data mining techniques and use the output to develop marketing strategies creatively to maximize shareholder value.

\section{REFERENCE}

1. Werner Reinartz, Manfred Krafft, And Wayne D. Hoyer, The Customer Relationship Management Process: Its Measurement and Impact on Performance, Journal of Marketing Research, 293 Vol. XLI (August 2004), 293-305)

2. Gupta, Sunil, Donald R. Lehmann, and Jennifer A. Stuart, Valuing Customers, Journal of Marketing Research, 2004, 41 (February), 7-18.

3. Darrll Rigby, Frederick F. Reichheld, Avoid the Four Perils of CRM, Harvard Business Review, 2002, (1): 101-109

4. Hugh Wilson1,Elizabeth Daniel and Malcolm McDonald, Factors for Success in Customer Relationship Management (CRM) Systems, Journal of Marketing Management, 2002, 18, 193-219

5. SAS Institute, From Data to Business Advantages: Data Mining, the SEMMA Methodology and SAS Software, SAS Institute: Cary, North Carolina, 1998.

6. Jiawei Han, Michelline Kamber, Data mining: conception and technology, Beijing: Mechanic Industry Publish, 2002.

7. Agnes Nairn, and Paul Bottomley, Cluster analysis procedures in the CRM era, International Journal of Market Research, Vol. 45 Quarter 2003

8. Koh Hian Chye, Chan Kin Leong Gerry, Data mining and customer relationship marketing in the banking industry, Singapore Management Review, 2002; 24, 2;

9. Claudio Marcus, A practical yet meaningful approach to customer segmentation, Journal of consumer marketing, Vol. 15 No. 5 1998, pp. 494-504

10. Andrew Banasiewicz, Acquiring high value, retainable customers, Database Marketing \& Customer Strategy Management, 2004, Vol. 12, 1, 21-31

11. Jon Kleinberg, Christos Papadimitriou, Prabhakar Raghavan, Segmentation Problems, Journal of the ACM, Vol. 51, No. 2, March 2004, pp. 263-280. 